\title{
Towards an automated economic assessment of innovative projects for the production of tonic Beverages
}

\author{
T. V. Kotova ${ }^{1,2, *}, A . V$. Medvedev $^{3}$, and A. N. Solopova ${ }^{3}$ \\ ${ }^{1}$ Ural State University of Economics, 620144 Ekaterinburg, Russian Federation \\ ${ }^{2}$ Kemerovo State Medical University, 650029 Kemerovo, Russian Federation \\ ${ }^{3}$ Plekhanov Russian University of Economics, 650992 Kemerovo, Russian Federation
}

\begin{abstract}
Over the past five years, in the country and in the world there has been an increase in the production and consumption of non-alcoholic tonic drinks (NTD). Representatives of various scientific schools are developing new NTD formulations. The regional characteristics of the used plant raw materials with a tonic effect are taken into account. The priority task of the food industry is to carry out activities aimed at making healthy food products, taking into account not only the traditions and habits of the population, but also the cost-effectiveness of introducing them into production. The paper considers the requirements of regulatory documentation for raw materials, elaborates the technological scheme of NTD production, describes the requirements for labeling and packaging of the finished drink. Introducing new technologies into production is an expensive process. The aim of the work is a preliminary automated assessment of the economic efficiency of an investment project for the production of NTD based on new recipes. The specified assessment is carried out from the point of view of traditional indicators of project efficiency, using the Karma optimization software package, which allows identifying the economic potential and finding the optimal characteristics of investment, production, financial activities of investment and production projects. The influence of the key indicator of the project (the market price of a unit of production) on the main indicators of the effectiveness of the investment project is studied. The life cycle is analyzed and the economic potential of the investment project is revealed through the use of an optimization mathematical model. The dependence of the net present value of the project on the planning horizon is described with a variation in the market unit price parameter. High characteristics of the economic efficiency of the investment project are obtained. Practical recommendations are given on sales markets, production technology, implementation of investment projects related to the production of NTD «Wild Cat».
\end{abstract}

\footnotetext{
*Corresponding author: t_kotova@inbox.ru
} 


\section{Introduction}

The modern NTD market is rapidly developing, which is confirmed by the research results of the famous international analytical company Euromonitor International [1]. Tables 1-3 show the dynamics of sales and consumption of NTD for 2014-2018 in Belarus, Russia's closest economic partner, and China and Kazakhstan, the region's closest neighbors with a potentially large consumer market.

Table 1. Retail volume of NTD, 2014-2018, \$ million.

\begin{tabular}{|l|c|c|c|c|c|}
\hline The country & 2014 & 2015 & 2016 & 2017 & 2018 \\
\hline China & 98,94 & 109,69 & 119,13 & 124,70 & 133,02 \\
\hline Kazakhstan & 0,51 & 0,57 & 0,62 & 0,67 & 0,73 \\
\hline Belarus & 0,20 & 0,23 & 0,24 & 0,26 & 0,28 \\
\hline Russia & 9,88 & 11,76 & 13,46 & 13,41 & 14,42 \\
\hline
\end{tabular}

Table 2. Revenue from the sale of NTD, 2014-2018, \$ million.

\begin{tabular}{|l|c|c|c|c|c|}
\hline The country & 2014 & 2015 & 2016 & 2017 & 2018 \\
\hline China & 1934,7 & 2381,7 & 2760,9 & 3150,1 & 3547,8 \\
\hline Kazakhstan & 37,5 & 41,9 & 51,6 & 56,6 & 64,5 \\
\hline Belarus & 16,5 & 14,2 & 15,4 & 18,6 & 21,6 \\
\hline Russia & 678,1 & 774,0 & 868,9 & 968,2 & 1066,3 \\
\hline
\end{tabular}

Table 3. Volume of consumption of NTD, 2014-2018, liters per year per 1 person.

\begin{tabular}{|l|c|c|c|c|c|}
\hline The country & 2014 & 2015 & 2016 & 2017 & 2018 \\
\hline China & 0,8 & 0,9 & 0,9 & 1,0 & 1,2 \\
\hline Kazakhstan & 0,4 & 0,4 & 0,4 & 0,4 & 0,3 \\
\hline Belarus & 0,2 & 0,3 & 0,3 & 0,4 & 0,4 \\
\hline Russia & 0,8 & 1 & 1,1 & 1,4 & 1,8 \\
\hline
\end{tabular}

Analysis of the data in the tables allows us to make a number of preliminary conclusions about the production of NTD in the period from 2014 to 2018 , there is an increase in total revenue from the sale of NTD. This is due to growing sales volumes, as well as increased consumer demand and rational product offerings of manufacturers. All countries are characterized by a uniform insignificant increase in retail sales in the analyzed period, with the lowest rate observed for Belarus $-\$ 0,28$ million. The volume of NTD consumption in Russia increased by $125 \%$ and amounted to 1,8 liters per year for 1 person. Since 2017, there has been a steady increase in NTD consumption. According to forecasts, the average Russian will consume 2,3 liters in 2019, and in 2020 - 2,9 liters.

The desire of consumers to have physical endurance, increased mental performance, mobility, encourages manufacturers of NTD to develop new formulations and technologies. They are produced not only by specialized enterprises such as Red Bull GmbH, but also by the leaders of the non-alcoholic industry - PepsiCo and Coca - Cola companies [2].

In the Siberian region, along with well-known international manufacturers and $\mathrm{OOO}$ "MegaPack" and RedBullGmbH , manufacturing soft drinks are engaged in small businesses: sole proprietor ("Tsirihidze O.O.", Omsk), LLC "Aqua-Vita" (Yurga, Kemerovo region). It is not easy to compete with small enterprises with production giants, but there are still quite good opportunities for promoting Russian brands on the domestic market. The question is the initial investment, positioning and quality of such products [3].

Almost all NTD, regardless of the brand under which they are produced, are produced in Russia. Consumers favor local brands as well as healthy foods. By combining extracts, 
fillers, elixirs, juices, flavors and other prescription ingredients, manufacturers are able to model drinks according to consumer preferences.

The expansion of the range of NTD is due to the use of additives: squeezed grapes; a mixture of tea (black long leaf or green); blueberry, nettle, blackcurrant leaves; rosehips, mountain ash, mountain ash; hibiscus flowers; honey; mummy extract; rosehip syrup; berry, fruit and herbal syrups; fruit or vegetable juices; oat flour; milk processing products, etc. [4].

Three main types are used as packaging: from polyethylene terephthalate (PET), a can, a glass bottle [5]. The most popular is can (59\%). In second place is a plastic bottle (19\%), and then a glass bottle. For $12 \%$ of consumers, packaging does not matter, however, glass containers are gaining more and more popularity every year. According to consumers, this type of packaging is considered more environmentally friendly.

The raw materials used for the production of NTD must comply with the requirements of regulatory documents. One of the main components of any drink is water. It must undergo the necessary treatment, according to GOST 2874 "Drinking water. Hygiene requirements and quality control". In addition, granulated sugar is used for the preparation of NTD (GOST 21-94), liquid sugar (GOST 18-170-74) or refined sugar (GOST 22-94). However, more often such products include cheaper sugar substitute sorbitol (a product of glucose hydrogenation), xylitol (GOST 20710-75). Caffeine, taurine, glucuronolactone, Lcarnitine, a complex of vitamins, various aromatic and flavoring additives, food colors are also used.

Raw materials and auxiliary materials used for the manufacture of plant-based NTDs must comply with the requirements of current regulatory documents and have the permission of the Rospotrebnadzor of Russia for use in the production of this type of product.

It is not allowed to process raw materials in which the residual amount of toxic elements exceeds the permissible levels established in the Unified Sanitary and Epidemiological and Hygienic Requirements for the Goods Subject to Sanitary and Epidemiological Supervision (Control) and the requirements of TR CU 021/2011.

The technological scheme for the production of drinks includes the following steps:

- acceptance of raw materials;

- preparation water;

- preparation and application of sugar syrup;

- preparation and application of a solution of citric acid;

- adding juices;

- adding flavorings and extracts;

- preparation and adding of a solution of preservatives (when using);

- preparation of blend syrup;

- pasteurization of blend syrup;

- transfer of blend syrup to the bottling line;

- preparation of the finished drink by mixing blended syrup and prepared water in a synchronous mixing apparatus and saturation with carbon dioxide (for carbonated drinks);

- bottling, capping, rejection, labeling, marking and group packaging, transfer of finished products to the warehouse;

- storage and transportation of finished products.

A technological feature of the production of the Wild Cat drink is the adding of concentrated juices and flavoring additives [6]. When preparing the blend syrup, the ingredients are added in the following sequence:

- chilled sugar syrup;

- an aqueous solution of citric acid;

- aqueous solutions of concentrated juices; 
- aqueous solutions of flavorings and extracts;

- an aqueous solution of a preservative;

- water to the estimated volume.

Pasteurization of blend syrup is carried out at a temperature of $85{ }^{\circ} \mathrm{C}$ for 30 seconds, followed by chilling to a temperature of $25-30{ }^{\circ} \mathrm{C}$. Bottling is done in PET bottles on the bottling line. Bottles with a drink are filled out with a label and labeled, indicating the production date and expiration date.

Marking should be carried out in accordance with the requirements of TR CU 022/2011, GOST R 52844-2007, indicating:

- phrases: "It is not recommended for people under 18 years of age, elderly and old, with hypertension, cardiac impairment, increased nervous irritability, severe atherosclerosis, people with insomnia, pregnant and lactating women," Shake before use, "Drink chilled ";

- quantitative content of tonic components (in $100 \mathrm{~cm} 3$ of drink);

- recommendations on limiting daily consumption (in packaging units) in accordance with the content of biologically active substances in consumer packaging and the values of the upper allowable levels of daily consumption: "It is recommended to use no more than one bottle (or $350 \mathrm{~cm} 3$ ) per day";

- recommendations for storing opened packaging: "Store opened packaging in the refrigerator for no more than 10 days".

The finished drink is checked for organoleptic and physico-chemical parameters (titratable acidity, mass fraction of solids), and also control the volume of filling and the correct labeling and marking.

Packages with drinks should be stored in clean, dry, covered, well-ventilated warehouses at temperatures from $0{ }^{\circ} \mathrm{C}$ to $18{ }^{\circ} \mathrm{C}$ and relative humidity not more than $75 \%$.

The introduction of new technologies into production is an expensive process, therefore, an important problem is the need for a preliminary assessment of the economic efficiency of an investment project for the production of NTD [7]. The aim of research is an automated optimization assessment of the economic efficiency of the NTD production project from the point of view of traditional indicators, using the optimization package of financial analysis programs built into the software of the automated complex [8] and allowing to identify the economic potential and find the optimal characteristics of investment, production, financial and financial-economic activities of investment and production projects.

To achieve this goal it is necessary to solve the following tasks:

- research the market of trade and consumption of NTD;

- analyze the production process of NTD "Wild Cat" based on new technology;

- apply a mathematical model of automated optimization assessment of the economic efficiency of projects based on technical and economic data produced by NTD "Wild Cat".

\section{Object and research methods}

For the automated optimization assessment of the economic efficiency of the project for the production of NTD, we use the mathematical model of work [9], which is the basis for the analysis of the project [10], for the production of agricultural products at the mesoscale. Input information into this model for P-O-B assay (pessimistic-optimistic-basic-analysis) is presented in Table 4. 
Table 4. The input data of the analytical model.

\begin{tabular}{|c|c|c|c|c|}
\hline $\begin{array}{l}\text { Item } \\
\text { № }\end{array}$ & Indicator, unit & $\begin{array}{l}\text { Value } \\
\text { pessimistic }\end{array}$ & $\begin{array}{l}\text { Value } \\
\text { basic }\end{array}$ & $\begin{array}{l}\text { Value } \\
\text { optimistic }\end{array}$ \\
\hline \multicolumn{5}{|c|}{ Characteristics of productive fixed capital assets (PFCA) } \\
\hline 1 & The cost of a set of PFCA, R million & 10 & 9,425 & 9 \\
\hline 2 & PFCA set performance, boot / PFCA set & 5000000 & 5920000 & 7000000 \\
\hline 3 & PFCA set service life, years & 3 & 5 & 7 \\
\hline \multicolumn{5}{|c|}{ Product specifications } \\
\hline 4 & Unit price (bottle), $\mathrm{R}$ & 20 & 35 & 50 \\
\hline 5 & The level of demand for products, $\mathrm{R}$ million & 150 & 210 & 250 \\
\hline \multicolumn{5}{|c|}{ Characteristics of production conditions } \\
\hline 6 & $\begin{array}{l}\text { Labor input (share of the wage fund in total production } \\
\text { costs), share }\end{array}$ & 0,1 & 0,05 & 0,03 \\
\hline 7 & $\begin{array}{l}\text { Material consumption (share of raw materials and } \\
\text { materials in total production costs), share }\end{array}$ & 0,91 & 0,84 & 0,77 \\
\hline \multicolumn{5}{|c|}{ Characteristics of external environment and project financing } \\
\hline 8 & Planning horizon, years & 5 & 5 & 5 \\
\hline 9 & Discount rate, share & 0,25 & 0,2 & 0,15 \\
\hline 10 & Maximum investment, $\mathrm{R}$ million & 1 & 10 & 100 \\
\hline 11 & Maximum loans, $\mathrm{R}$ million & & 0 & \\
\hline 12 & Maximum subsidies, $\mathrm{R}$ million & & 0 & \\
\hline \multicolumn{5}{|c|}{ Characteristics of taxation (simplified form) } \\
\hline 13 & Single tax "Percentage of profit", share & 0,06 & 0,06 & 0,06 \\
\hline
\end{tabular}

Note several of these features in table 4 of the project under consideration for the production of NTD. The relatively low cost of fixed assets (about $10 \mathrm{R}$ million) is aggravated by characteristic the high consumption rates of production for such projects [8], which is determined, respectively, by the high cost of raw materials and materials used. NTD production is carried out in conditions of small and medium-sized enterprises, which are usually taxed in a simplified form. In addition, it assumes borrowed financing of fixed assets (taken into account in the discount rate) and the absence of loans to finance current costs, which is often caused by the short payback period of such projects. The level of demand for products is estimated from regional market conditions (on the example of the Kemerovo region). In particular, it is assumed that all manufactured products will be sold at the indicated base market price.

Automated assessment of the economic efficiency of the project for the production of NTD is carried out using the "Karma" software package, which allows for an operational, multi-parameter, optimization analysis of the projects for all of the tables 1 parameters. Consider the impact on the economic efficiency of the project of such a key indicator as the market price of a unit of production. In Figure 1 shows the parametric dependencies of the added (to the investments made) value of project on the planning horizon, with a variation in the market unit price parameter $(0.350 \mathrm{~cm} 3$ bottles $)$. 


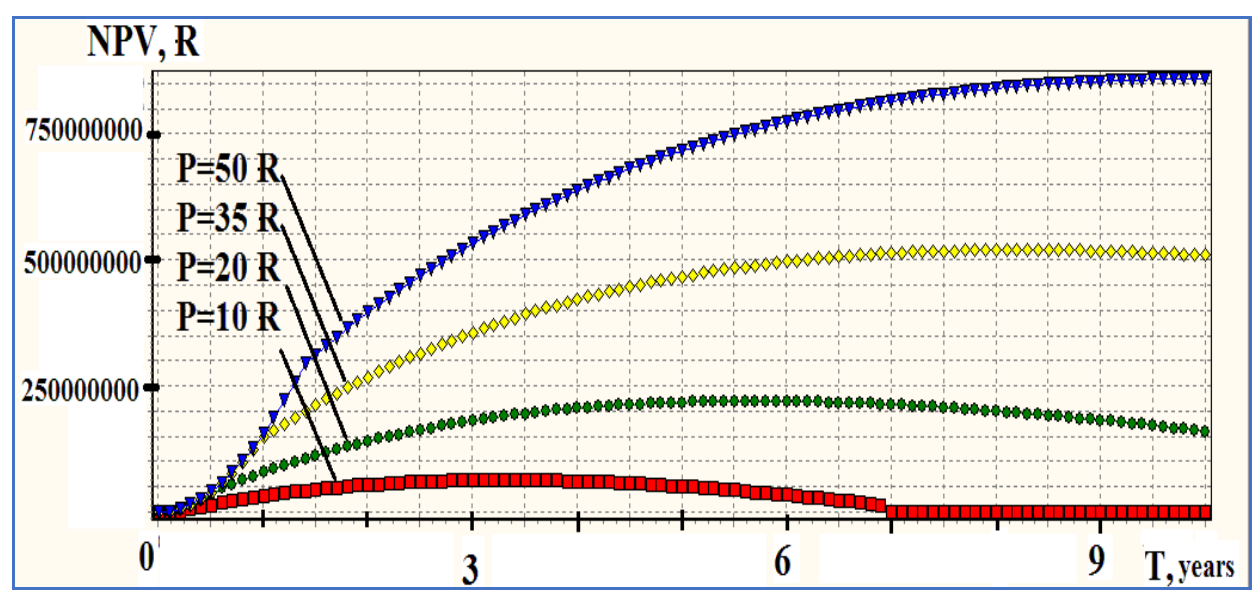

Fig. 1. Dependence of NPV (in rubles) of the project on the planning horizon when varying the market unit price parameter.

\section{Results and discussion}

From figure 1, an analyst can, for example, evaluate the features of the project's life cycle, potential (maximum values) of its added value, payback period, optimal reinvestment times, and also obtain other information, depending on the effect of which parameter on the distribution under consideration is being studied. In particular, the figure shows that, at a unit price of $\mathrm{P}=50 \mathrm{R}$, there is a characteristic dependence of the project's life cycle that is absolutely stable over the entire planning horizon, at $\mathrm{P}=35 \mathrm{R}$, an optimum point of $\mathrm{T} \approx 8$ years appears on the life cycle graph, which indicates the feasibility of reinvesting in the project at the moment of its development. A further decrease in the market price $(\mathrm{P}=20 \mathrm{R})$ leads to a decrease in the economic potential of the project and a shift in the optimal moment of reinvestment $(\mathrm{T} \approx 5$ years) in it. At $\mathrm{P}=10 \mathrm{R}$, the graph of the given dependence already indicates the exhaustion of the economic potential of the project at time intervals which are comparable with the planning horizon, and at $\mathrm{P}=5 \mathrm{R}$ the project becomes unprofitable.

Table 5 shows the characteristics of the economic efficiency of the project for the production of NTD during P-B-O (pessimistic-basic-optimistic) analysis according to the parameter of the market price of a unit of production $\mathrm{P}=20-35-50 \mathrm{R}$.

Table 5. Characteristics of the economic efficiency of the project when conducting a P-B-O analysis on the parameter of the market price of a unit of production.

\begin{tabular}{|l|l|}
\hline Indicator & Indicator value \\
\hline Direct investment financing, R million & 9,425 \\
\hline Period of reinvestment in the project ( P-B-O ), years & $4,5-8-\infty$ \\
\hline Net present value of the project (NPV) ( P-B-O ), R mln & $217-463-716$ \\
\hline Internal rate of return (IRR) (P-B-O), \% & $700-1490-2120$ \\
\hline $\begin{array}{l}\text { Payback period (PP) from the moment of the beginning of product sales } \\
\text { (P-B-O), weeks }\end{array}$ & $4-3-2$ \\
\hline
\end{tabular}

The indicators given in table 5 characterize this project as highly cost-effective, which is not surprising, since the capital productivity ratio of PFCA (with a basic set of key parameters) exceeds 20 units. In addition, it should be noted that the obtained high performance characteristics of the analyzed project are achieved under the conditions of applying the simplified form of taxation (single tax of $6 \%$ of profit). Using a more stringent 
taxation of options (for example, a single tax of $15 \%$ of revenues and, moreover, full forms of taxation with calculation of added value, property tax, income, insurance payments to social funds, etc.) Make this project ineffective: The optimal net present value (NPV) becomes zero. In this regard, we will conduct additional testing of the effectiveness of the project under study from the point of view of production parameters such as material and labor intensity, choosing pessimistic values of some key project parameters, for example, unit price $\mathrm{P}=20 \mathrm{R}$. In particular, we consider the influence of these parameters on such project's characteristics as the life cycle and optimal performance of the PFCA set (see Figure 2).
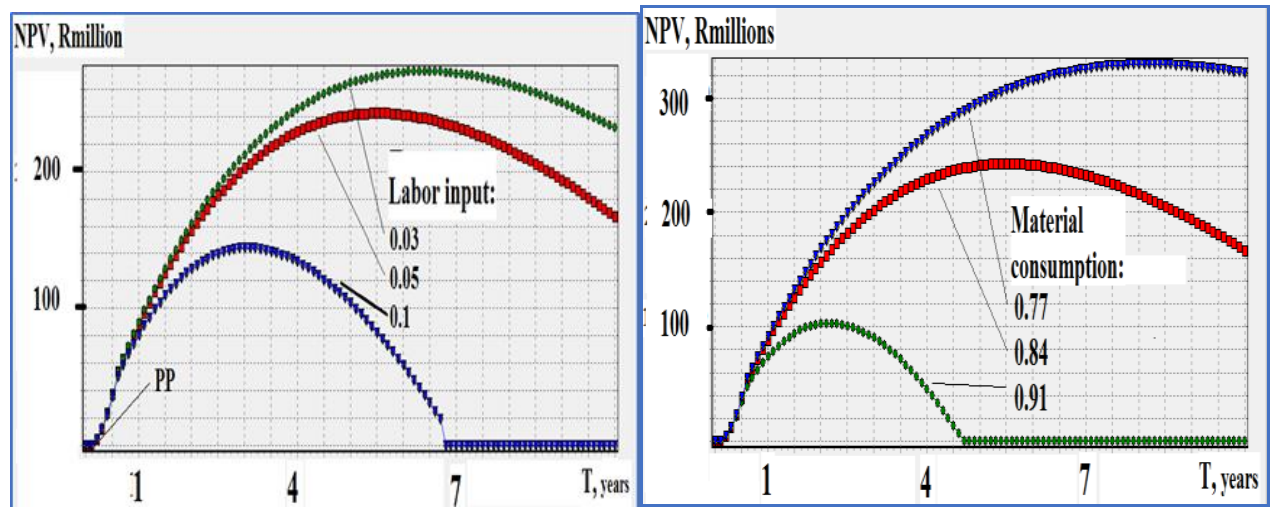

Fig. 2. Dependences of the NPV of the project on the planning horizon $T$ when varying labor input parameter (group of graphs on the left) and material consumption (group of graphs on the right).

Figure 2 shows dependencies of NPV project on planning horizon T. As indicated above, these graphs represent the project life cycle, including the absolute values of NPV, optimal payback periods, periods reinvestment, properties projects stability on planning horizons etc. As can be seen from the figure, with the growth of labor input (figure on the left) and material consumption (figure on the right) from optimistic to pessimistic values, life cycle indicators deteriorate, falling, relative to the base value of material consumption, by about 2,4 times the maximum NPV and 2,75 times for the optimal period of reinvestment (respectively, 1,9 and 1,8 times for labor input).
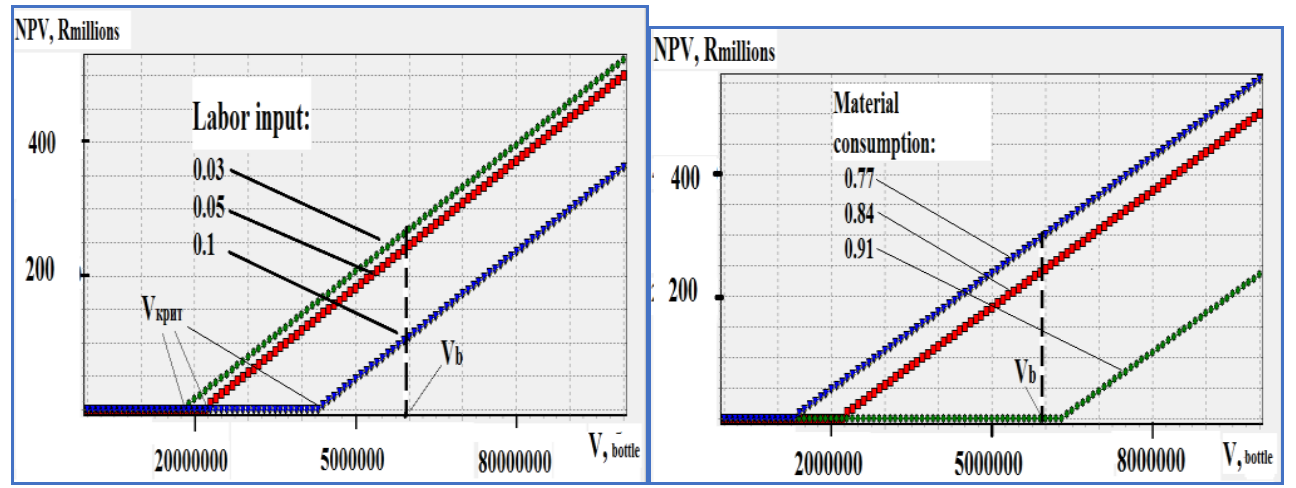

Fig. 3. Dependences NPV (in rubles) of the project on the productivity V set of PFCA when varying the labor input parameter (group of graphs on the left) and material consumption (group of graphs on the right). 
Figure 3 shows the dependences of the NPV project on the performance of the V set of PFCA. According to the graphs shown in the figures, the investment analyst, as well as the marketer, can get an idea of the optimal production indicators of the project. In this case, one can simulate both a situation where the analyst needs to determine the maximum productivity, provided that there is a stable market segment for the company to sell its products (that is, the company operates at the maximum of its capacities), and a situation where it is necessary to determine the effectiveness of the project in terms of entering the market and uncertainties in demand for products (that is, an enterprise may underload its production capacities). As can be seen from figure 3, increasing labor input (figure on the left) and material consumption (figure on the right) project investment becomes profitable with ever increasing values (graphs separation point of the abscissa axis) performance $\mathrm{V}_{\text {crit }}$ set PFCA. At the same time, an investment analyst can obtain the corresponding approximate values of $\mathrm{V}_{\text {crit }}$ without conducting time-consuming and often expensive marketing research. In particular, from the graphs in Figure 3 it follows that for the payback of the project (at a unit price of $\mathrm{P}=20$ and basic values of material consumption and labor input), the enterprise should produce at least 2 million and 2.2 million bottles of drink per year, respectively. Given that the base value of $\mathrm{V}_{\mathrm{b}}=5,92$ million bottles, we can draw an obvious conclusion from the graphs about the payback of the project, as well as estimate the absolute values of the economic effect by the NPV indicator at the level of $240 \mathrm{R} \mathrm{mln}$.

The traditional component of the preliminary analysis of any investment project is the assessment of producer losses when using various financial schemes for the implementation of the project. Consider the following formulation of this problem. It is necessary to compare the effects of the investment project through NPV, if implemented only from its own manufacture's investment funds and, if implemented only borrowed investment funds. In the first case, the discount rate $r$ of the project contains only the inflation component, which is taken here as $5 \%$ per annum (optimistic value in table 1), and in the second, in addition to the inflation rate, the percentage of investor requirements, taken here as $15 \%$ per annum, which gives the total value of $r=20 \%$. In other words, this computational experiment allows us to assess the impact on the investment project of financial leverage of any size (in this case, $15 \%$ ).

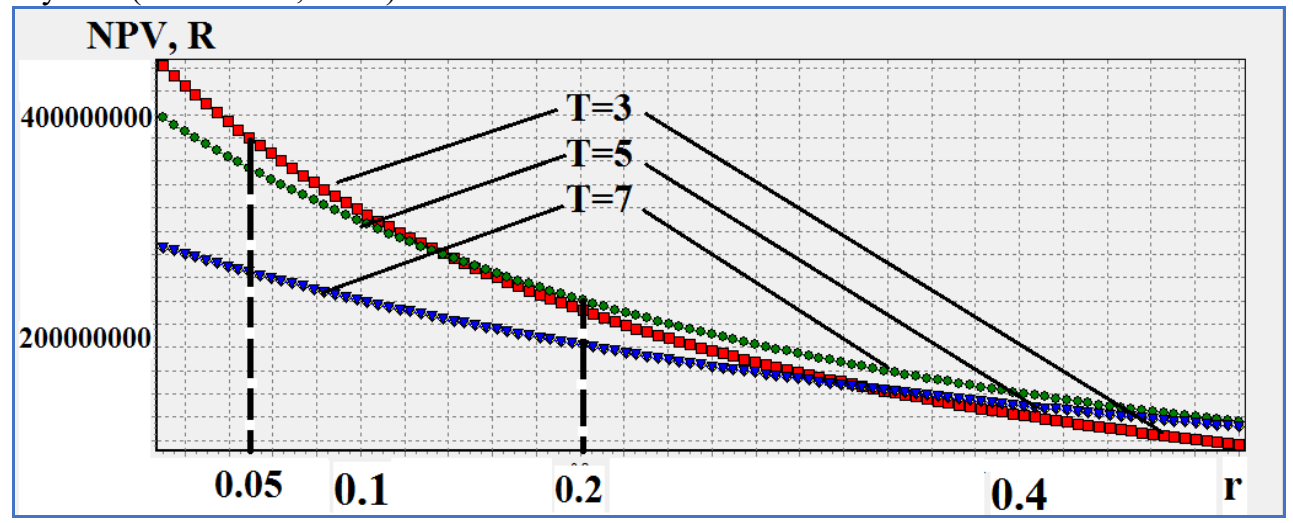

Fig. 4. Dependences of the NPV of the project on the discount rate $r$ of the project when varying the planning horizon $\mathrm{T}$.

Figure 4 shows the dependences of the NPV of the project on the discount rate $r$ of the project, allowing financial analysts to quickly and easily evaluate the losses of the manufacturer using the full financial leverage of the project, varying any of its parameters. According to the data shown in the figure, the losses of the NPV project when varying the planning horizon (3, 5 and 7 years) are approximately $26 \%, 29 \%$ and $32 \%$. 
The automated tools used in the work [8] allow for a comprehensive, optimization of investment, production and financial analysis of projects, including highlighting of all optimal income and expense streams, varying several selected parameters at once. For example, under the assumption that in a project, for various reasons, of a production, financial nature or under the influence of the market environment, both the price $\mathrm{P}$ of the unit of production and the productivity of the V set of OPF ( Wild Cat NTD production plant ) can change, we will carry out analysis of the project life cycles, giving the pair $(\mathrm{P}, \mathrm{V})$ cross-values according to the scheme $\left(\mathrm{P}_{\mathrm{b}}, \mathrm{V}_{\mathrm{b}}\right) \rightarrow\left(\mathrm{P}_{\mathrm{o}}, \mathrm{V}_{\mathrm{p}}\right) \rightarrow\left(\mathrm{P}_{\mathrm{p}}, \mathrm{V}_{\mathrm{o}}\right)$, where the indices are "p", "b", "o" correspond to the pessimistic, basic and optimistic values of the parameters from table 1 (in accordance with rules P-B-O-analysis).

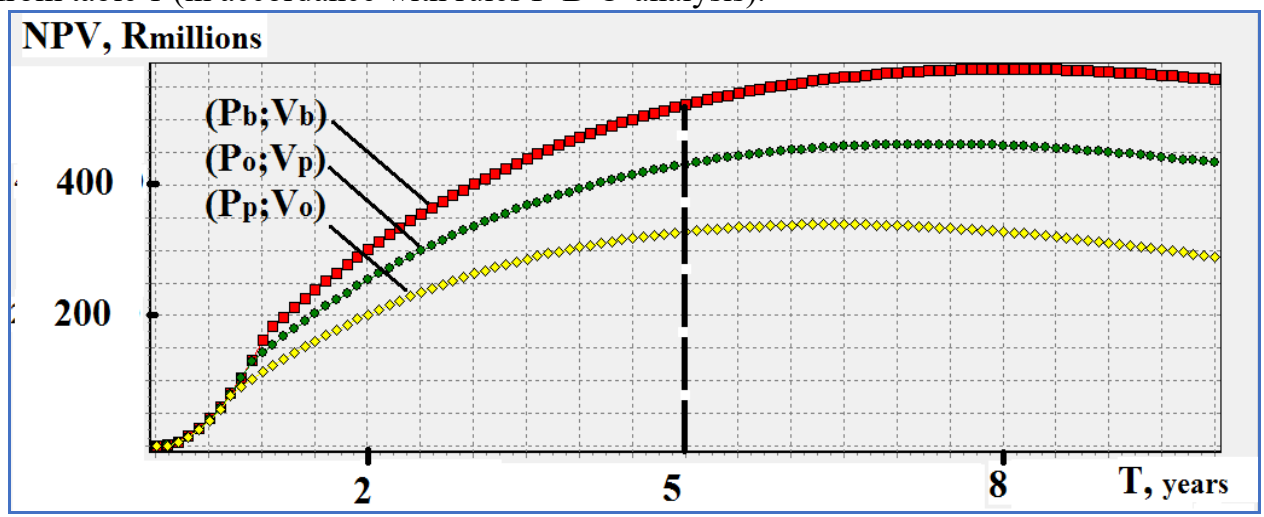

Fig. 5. Dependences of the NPV of the project on the planning horizon $T$ with varying pairs $(P, V)$.

Figure 5 shows the results of the P-B-O analysis of the life cycles of an investment project for the production of NTD «Wild Cat» with varying pairs $(\mathrm{P}, \mathrm{V})$. The information presented in the figure allows an investment analyst to carry out a comparative multiparameter analysis of projects on several key parameters at once. For example, from Figure 5 it follows that the choice of the pessimistic value of the price parameter $\mathrm{P}$ of the unit of production is preferable to the choice of the pessimistic value of the performance parameter V of the PFCA set (factory of NTD «Wild Cat»), since in the first case the loss of economic effect from the project (middle graph) less losses in the second (lower graph) on the entire planning horizon.

\section{References}

1. Euromonitor International Research, URL: http://www.foodmarket.spb.ru/current.php?article=1204

2. Alaa Bani Hani, Jinous F. Tahmasseb, Sports and Energy Drinks, 39 (2019)

3. Energy Beverages Production - Investment Search Application for startupnetwork.ru, URL: https://startupnetwork.ru/projects/353120.html

4. Ph. R. Ashurst, R. Hargitt, F. Palmer, Soft Drink and Fruit Juice Problems Solved, 29 (2017)

5. Wilson José Fernandes Lemosunior, Luana Pereira do Amaral dos Reis, Vanessa Sales de Oliveira, Léo Oliveira Lopes, Karen Signori Pereira, Food Control, 329 (2019)

6. T.V. Kotova, A.S. Cheremichkina, Technique and technology of food production, 148 (2012)

7. C. Pinna, M. Demartini, F. Tonelli, S. Terzi, How Soft Drink Supply Chains drive sustainability: Key Performance Indicators (KPIs) identification, 862 (2018) 
8. A.V. Medvedev, M.N. Roslov, A.S. Ukhov, Certificate 2018617155. Generator and linker of decision support software in situational centers of socio-economic development, declared 08/05/2016; publ. 10.01.2017. URL: http://www1.fips.ru/Archive/EVM/2016/.

9. A.V. Medvedev, International Journal of Applied and Fundamental Research, 622 (2015)

10. E. A. Fedulova, Foods and Raw Materials, 154 (2016) 